\title{
Serological identification of Streptococcus sanguis and Str mitior
}

\author{
LYN C BALL \\ From the Division of Hospital Infection, Central Public Health Laboratory, Colindale, London NW9
}

SUMMARY A total of 165 strains of Streptococcus sanguis and Str mitior were selected on the basis of their biochemical reactions using established identification procedures. These strains were also $\dot{c}$ classified using API Database and were then screened against five candidate grouping sera. Biochemical tests and serological identification were in general complementary, but no regular associations between biotype and serological reaction were observed.

The introduction of the Lancefield grouping method brought order to the pyogenic streptococci, but biochemical methods have proved useful in defining species among the viridans streptococci. The classification of some of these streptococci-for example, Streptococcus bovis or Str mutans-is now reasonably precise. Further work is needed on the organisms known as Str sanguis, and the relation of these streptococci to Str mitior needs to be clarified. The particular value of some recently introduced systems is that new tests are being applied to the identification of streptococci ${ }^{1}$; however, these new tests do not help to delineate Str sanguis and Str mitior. This paper describes a re-examination of some representative strains of these two species for carbohydrate antigens that might be comparable to Lancefield group antigens.

\section{Material and methods}

STRAINS

A collection of 165 strains, nearly all of which were isolated from blood cultures, were selected after being identified as either dextran positive or dextran negative varieties of Str sanguis or Str mitior (Table 1). Reference strains obtained from the NCTC were $\vec{\varphi}$ numbered $3165,7863,7864,7865,7868,7869$, or 7870, 7872, 9124, 10231, and 11085. Those from the ATCC were numbered 8144 and 12396. The cultures Kiel 56, Jena 88, S56, and FW225 were obtained from within the Division.

The identification scheme used has been $\overparen{\otimes}$ described elsewhere.' The API 20 Strep gallery forms part of that scheme.

\section{SEROLOGICAL METHODS}

Antisera were prepared against group $\mathrm{H}$, strain Blackburn (NCTC 10231), the "group W" (NCTC $11085)^{2}$ and Dr Lancefield's strains Perryer (F90A, ATCC 12396) ${ }^{3}$ and K208 (ATCC 8144). ${ }^{3}$ The strain Blackburn is used in the Streptococcus Reference Unit for the production of group $\mathrm{H}$ antisera, but the strain Perryer has been used for the same $O$ purpose in the USA. Group $\mathrm{H}$ antiserum was also

Table 1 Results of serological tests on the 165 strains, subdivided by the criteria of Parker and Ball*

\begin{tabular}{|c|c|c|c|c|c|c|}
\hline & & F90A & “Group W" & Group $\mathrm{H}^{\dagger}$ & Multiple reactions & No reactions \\
\hline $\begin{array}{l}\text { Str sanguis } \\
\text { (Arg + Aesc }+) \\
\text { Str sanguis } \\
\text { (Arg - Aesc }+ \text { ) } \\
\text { Str sanguis } \\
\text { (Arg + Aesc-) } \\
\text { Str mitior } \\
\text { (Arg - Aesc-) }\end{array}$ & $\begin{array}{l}\text { Dex+ } \\
\text { Dex- } \\
\text { Dex+ } \\
\text { Dex- } \\
\text { Dex+ } \\
\text { Dex- } \\
\text { Dex+ } \\
\text { Dex- }\end{array}$ & $\begin{array}{l}1 \\
9 \\
0 \\
1 \\
0 \\
0 \\
0 \\
0\end{array}$ & $\begin{array}{r}7 \\
2 \\
1 \\
0 \\
2 \\
0 \\
10 \\
3\end{array}$ & $\begin{array}{r}16 \\
7 \\
0 \\
0 \\
2 \\
0 \\
3 \\
2\end{array}$ & $\begin{array}{l}7 \\
6 \\
0 \\
7 \\
1 \\
1 \\
2 \\
2\end{array}$ & $\begin{array}{r}5 \\
24 \\
4 \\
0 \\
5 \\
5 \\
10 \\
20\end{array}$ \\
\hline
\end{tabular}

*Seventy six of the strains produced dextrose from sucrose.

†Group H Blackburn (NCTC 10231) and Wellcome CN2814 gave identical results.

Aesc $=$ hydrolysis of aesculin .

Arg $=$ hydrolysis of arginine.

Dex = production of extracellular polysaccharide dextran. 
purchased from the Wellcome Laboratories.

Vaccines were prepared by growing the cultures in Todd-Hewitt broth (Media Department, CPHL). The bacterial cells were washed in saline, digested with trypsin, rewashed, and sterilised by heating at $56^{\circ} \mathrm{C}$ for $30 \mathrm{~min}$. The cells were concentrated 10 fold over that in the original broth culture and were administered in $1 \mathrm{ml}$ doses. Rabbits were injected intravenously, twice weekly, for a maximum period of six weeks.

Antigen extracts were prepared from all the strains using formamide ${ }^{4}$ and the hot acids $(0 \cdot 2 \mathrm{~N}$ $\mathrm{HCl} 100^{\circ} \mathrm{C}$ for $10 \mathrm{~min}$ ) procedures. Precipitin tests were performed by double diffusion in agarose $(1 \%$ $\mathrm{wt} / \mathrm{vol}$, Koch-Light) in distilled water, and the slides were incubated overnight at room temperature. Immunoelectrophoresis was carried out in barbitol buffer at $\mathrm{pH} 8.6$ by standard methods. ${ }^{6}$

\section{Results}

The strains in this study were selected on the basis of their reactions in the identification system used by Colman and Ball.' All 165 strains examined fell into one or other of the dextran positive or dextran negative varieties of Str sanguis or Str mitior. A total of 97 strains were allocated to the Str sanguis aggregate, of which 51 were dextran positive and 46 dextran negative. The remaining 68 were representatives of Str mitior and 28 formed dextran and 40 did not.

Because the API 20 strep gallery was included in the identification scheme the profile numbers were available and were compared with the API Database (API Lab, Basingstoke). With their usage of names 123 strains were categorised as Str sanguis, of which 79 fell into their Str sanguis I and 44 their Str sanguis II. A further 20 strains were classed as Str mitis I or Str mitis II. What were termed unacceptable profiles were obtained with 22 strains. There was no apparent association between any of these categories and the results of the serological tests.

Parker and Ball ${ }^{7}$ used an arbitrary scheme for the division of strains such as those used in this study. They used the hydrolysis of aesculin, the formation of dextran, and the production of ammonia from arginine as key characteristics. The subdivision of the 165 strains in this way and a comparison with the results of the serological tests is shown in Table 1. In that scheme any strain that gave a positive reaction in any two or more of the three tests was placed in Str sanguis, and strains that hydrolysed neither aesculin nor arginine were placed in Str mitior. This gave two large groups of strains. One reacted with the group $\mathrm{H}$ antisera and hydrolysed both substrates. Of these 42 strains, $24(57 \%)$ formed dextran and would have been reported as representatives of the dextran positive variety of Str sanguis.' Another notable set reacted with the "group W' antiserum but hydrolysed neither aesculin nor arginine. Ten of $13(77 \%)$ of these strains produced dextran from sucrose and would have been classed as dextran positive Str mitior.

The distribution of the serological reactions among all 165 strains is shown in Table 2. Neither acid nor formamide extracts of 79 strains (48\%) reacted with any of the five candidate sera. Of the 25 strains (15\%) that reacted with "group W," $80 \%$ produced dextran, 30 strains $(18 \%)$ reacted with the Colindale group H Blackburn strain, of which $64 \%$ produced dextran. Apart from the strains, mentioned above, that reacted with either group $\mathrm{H}$ or "group W," a useful collection of 11 strains (7\%) reacted with sera produced against the strain F90A. Of these only one strain produced dextran. Multiple reactions were shown by 20 strains. That is, extracts

Table 2 Distribution of serological reactions among the 141 strains that had acceptable profiles in the API Database*

\begin{tabular}{|c|c|c|c|c|c|}
\hline & \multicolumn{2}{|c|}{ Str sanguis } & \multicolumn{2}{|l|}{ Str mitis } & \multirow{2}{*}{$\begin{array}{l}\text { Total } \\
\text { no } \\
\text { positive }\end{array}$} \\
\hline & Dex-ve & Dex $+v e$ & Dex-ve & Dex $+v e$ & \\
\hline $\begin{array}{l}\text { Group } \mathrm{H} \text { antiserum } \\
\text { "Group W" antiserum } \\
\text { F90A antiserum } \\
\text { K208 antiserum } \\
\text { Multiple reactions } \\
\text { No reactions }\end{array}$ & $\begin{array}{r}7 \\
5 \\
10 \\
0 \\
6 \\
26\end{array}$ & $\begin{array}{r}18 \\
17 \\
0 \\
0 \\
10 \\
24\end{array}$ & $\begin{array}{r}0 \\
0 \\
0 \\
0 \\
1 \\
17\end{array}$ & $\begin{array}{l}0 \\
1 \\
0 \\
0 \\
1 \\
0\end{array}$ & $\begin{array}{l}30 \dagger \\
25 \\
11 \\
0 \ddagger \\
20 \S \\
79\end{array}$ \\
\hline
\end{tabular}

*For example, of the 30 strains allotted to group H, 25 were classed as Str sanguis by their criteria.

tIdentical reactions with both Colindale and Wellcome antisera.

¥Reacted with "Group W."

$\S$ Multiple reactions

"Group W"/F90A

“Group W"/F90A/Group H

"Group W"/Group H

F90A/Group H

"Group W"/K208

Dex $=$ production of extracellular polysaccharide dextran.

The names used in this table were obtained from the API database. 
of these strains yielded lines of identity with stock extracts of more than one of the immunising strains.

\section{Discussion}

The importance of Str sanguis in subacute bacterial endocarditis is well known. Indeed the original name of this species was "streptococcus sbe," which was subsequently changed to Str sanguis ${ }^{8}$ That some of these strains carry one or other of the antigens, known as group $\mathrm{H}$, has been documented. ${ }^{39}$

With the introduction of new biochemical tests, the identification of streptococci has become much easier. A problem remains with the Str sanguis aggregate, however, for the tests that have been introduced have proved most useful with other species. For example, the Voges-Proskauer reaction and the phosphatase test have helped the identification of Str milleri, and pyrrolydonylarylamidase with Str pyogenes. ${ }^{1}$

This investigation was begun with the hope that there would be an association of biotype with antigen, leading eventually perhaps to a serological test that would help in the diagnosis of subacute bacterial endocarditis. The results obtained with the five antisera show that irrespective of whatever biochemical identification procedure was used, there was no close association between biotype and possession of a particular antigen. Furthermore, the expectation that a small number of antigens would cover most of these organisms was not confirmed. Over half the strains showed no reaction with five antisera.

The status of the so called multiple reactions is unclear. Lines of identity were formed with extracts of reference strains. Had a single antiserum, "group W' for instance, been used then an additional 17 strains would have been allotted to that category. Two obvious explanations are either that the strains showing these multiple reactions carried two separate antigens or that they were merely different determinants on the one antigen. These possibilities were not examined.
The approach that has been used in this study was weighted towards established extraction procedures. It is, of course, possible that a novel antigen might be species specific. Although the employment of serology as the only method of identification would be inefficient, the use of both biochemical and serological tests could be useful in studying various aspects of the diseases caused by these streptococci. Finally, it has been confirmed that the antigens known as " $\mathrm{H}$ " and " $\mathrm{W}$ " are broadly distributed among the species examined.

I would like to thank Dr G Colman for his help and encouragement.

\section{References}

' Colman G, Ball LC. Identification of streptococci in a medical laboratory. J Appl Bacteriol 1984;57:1-4.

${ }^{2}$ Henriksen SD, Eriksen J. Characterisation of a new group specific antigen of Streptococcus sanguis. Immunochemistry 1978; 15:761-5.

${ }^{3}$ Colman G. The classification of streptococcal strains. London: University of London, 1970. PhD Thesis.

${ }^{4}$ Fuller AT. The formamide method for the extraction of polysaccharides from haemolytic streptococci. Br J Exp Pathol 1938; 19:130.

${ }^{5}$ Lancefield RC. The antigenic complex of Streptococcus haemolyticus. I Demonstration of a type-specific substance in extracts of Streptococcus haemolyticus. J Exp Med 1928;47:91.

- Sargent JR, George SC. Methods of zone electrophoresis. Poole, England: BDH Chemicals, 1975.

' Parker MT, Ball LC. Streptococci and aerococci associated with systemic infections in man. J Med Microbiol 1976;9:275-302.

${ }^{8}$ White JC, Niven CF Jr. Streptococcus sbe: A streptococcus associated with subacute endocarditis. $J$ Bacteriol 1946;51:711-22.

' Colman G, Williams REO. Taxonomy of some human viridans streptococci. In: Wannamaker LW, Matsen JM, eds. Streptococci and streptococcal diseases: recognition, understanding and management. London: Academic Press, 1972:281-99.

Requests for reprints to: Mrs LC Ball, Division of Hospital Infection, Central Public Health Laboratory, Colindale Avenue, London, NW9 5HT, England. 